
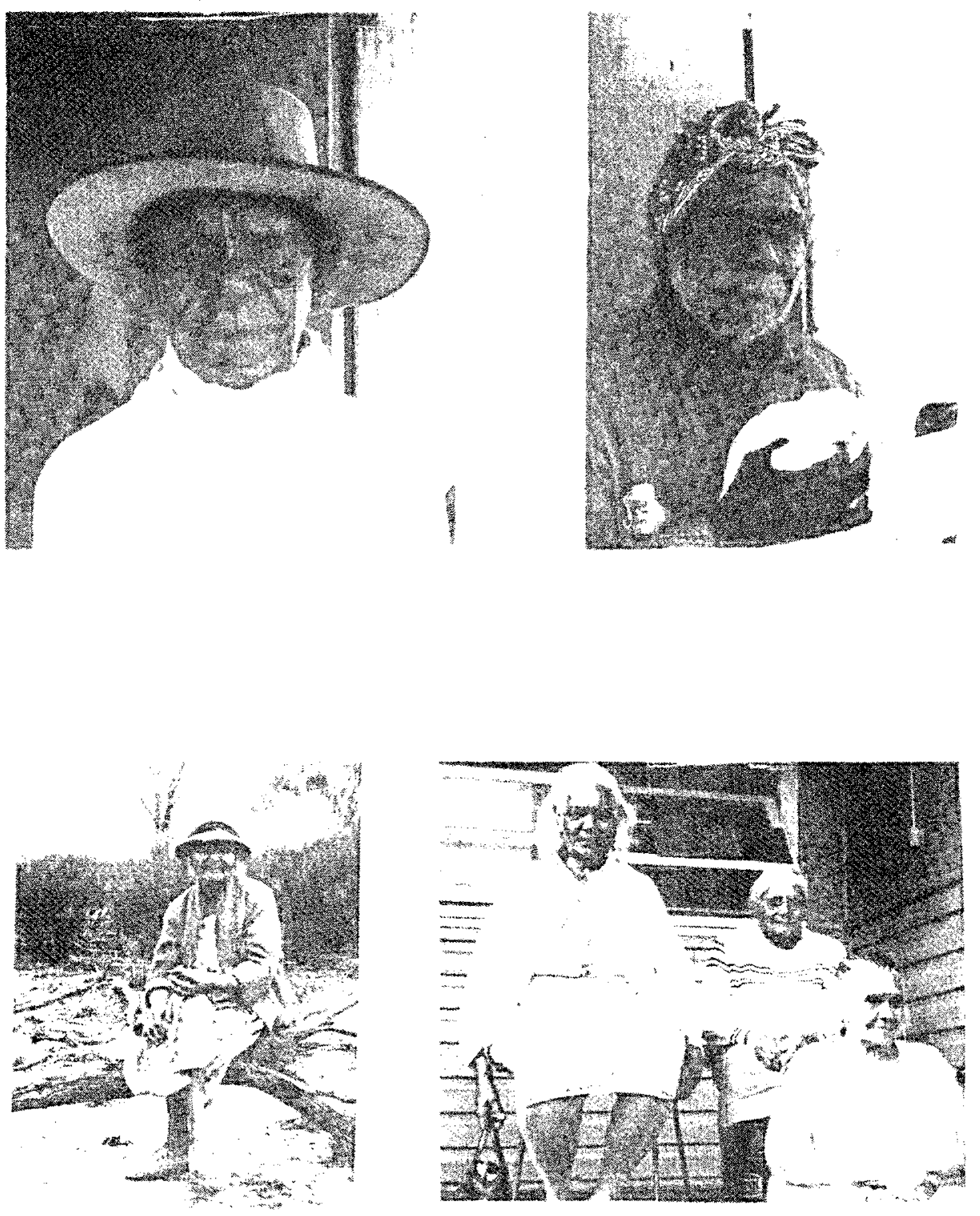

Top left: Mr Jimmy Russell

Top right: Mr Leslie Russell

Photographs by Graham Hercus

Lower left: Mrs Sarah Johnson

Lower right: Mrs Lily Hampton, Mrs Lizzic Williams, Mrs Fliza Kennedy

Pholographs by. Tamsin Donaldson? 


\section{TRANSLATING ORAL LITERATURE: ABORIGINAL SONG TEXTS}

\section{Tamsin Donaldson*}

This essay discusses what is involved in making oral literature in Australian languages, especially songs, accessible to speakers of English. It offers a variety of linguistic, technical and above all historical and cultural reasons why so little has been attempted, and why so few of the attempts have been successful. In the course of the essay, I introduce a sprinkling of examples from an extensive oral literature whose full range remains unknown, and whose particular regional traditions are for the most part disappearing as the number of knowledgeable practitioners dwindles. My hope is that these examples will arouse interest in the creation of more and better 'translations', in the sense developed here.

The Aboriginal inhabitants of Australia first felt the impact of European invasion between the later eighteenth century and the early twentieth century. Before this invasion the Aborigines of mainland Australia numbered somewhere in the region of 300,000 . Between them they probably spoke more than two hundred different languages. ${ }^{1}$ Most of these languages had a variety of named dialects, and one way in which people identified themselves was as 'owning' a dialect (or sometimes more than one) by virtue of their descent.2 Calculation of the number of distinct languages spoken over the continent is complicated by difficulties attaching to the use of the terms 'language' and 'dialect', as well as by the small amount of surviving information about some areas. Varieties of speech recognised socially as being different might or might not be closely related in terms of shared grammatical characteristics or mutual intelligibility.

Acquaintance with more than one language was a familiarfeature of Aboriginal life. Marriage frequently linked speakers of different languages, and children regularly grew up with knowledge of languages other than the first they learned to speak. In some areas there were also special sublanguages which had to be used in the presence of certain relatives, or on secret ceremonial occasions.

\footnotetext{
* This article is based on an address, with tape-recordings of my examples, given at the conference on literary translation held in May 1977 at the Humanities Research Centre, Australian National University. My work with Ngiyambaa speakers was supported by a grant from the Australian Institute of Aboriginal Studies.

1 Tindale's (1974) map gives an impression of the distribution of their speakers. But there are many problems associated with any attempt to map Aboriginal social and linguistic divisions, among them the fact that there is no neat coincidence between linguistic affiliation and land ownership. For a comprehensive introduction to the languages of Australia, see Dixon 1980.

2 For examples of ways in which languages or dialects are 'owned', see Sutton 1978, especially Appendix 2.
} 
The linguistic habits of those Aboriginal communities which survived colonization have changed along with their life-styles, more or less drastically according to the length and nature of the non-Aboriginal presence. Initially, at least, people were exposed to an even greater variety of linguistic experience as they were forced from their home territories into closer contact with speakers of other vernaculars, and encountered English and sometimes other non-Australian languages. But everywhere the result so far has been a progressive threat to the viability of the Australian languages. Something like fifty of them now appear to be extinct, a hundred have fewer than ten speakers, and the remainder are in various states of health, with only about a dozen having more than five hundred speakers. ${ }^{3}$

My first examples of oral literature were contributed by the last generation of the Wangaaybuwan people who can still speak their language, Ngiyambaa. They were born around the turn of the century in the dry country to the northeast of Ivanhoe in central western New South Wales, north of the Lachlan and east of the Darling. As well as being the only fluent Ngiyambaa speakers, they are the only people who have personal memories of the last initiation ceremonies which were held in their territory, in 1914. One man who was 'put through the rules' then is still alive. He is, as far as he knows, the only living person to have been through even the first stages of initiation in western New South Wales.

At the time of these ceremonies, members of this generation were already learning English. In 1914 the last Wangaaybuwan person who never spoke English was already middle-aged. None of the young people growing up were of wholly Aboriginal descent - as one of this generation put it, 'Our grandmothers were taken advantage of'. The kinship system was under pressure, people were 'marrying wrong', and only one woman alive today was able to marry a man of the appropriate kinship category (what they called 'right meat' for her). ${ }^{4}$ Their physical world had undergone dramatic changes too: one of the animals in the totemic clan system, the rabbit-eared bandicoot, was already ex tinct.

More than half a century later members of this generation recall some of the stories they learnt as children, and a number of songs composed well into the 1920 s by people a generation older than themselves. When these songs were first sung to me, I realised how important song-making

3 Sutton 1975.

4 For a description of traditional social organisation and marriage rules among the Wangaaybuwan see Beckett 1959. The major source of this information was Fred Biggs, composer of the second Ngiyambaa song presented here. 
was to the Wangaaybuwan. 5 They had continued to make and enjoy songs in Ngiyambaa when the traditional culture as a whole was under great stress. Indeed, one of the ways in which they responded to the rapid changes overtaking their way of life was to make songs expressing their reactions. ${ }^{6}$

The words of the songs which survive usually consist of up to half-adozen economically evocative sentences. The lines do not form a narrative sequence, but include a high proportion of questions, imperatives, exclamations and suppositions as well as plain statements. They are not formally different in any way from spoken sentences of the language either in grammar or vocabulary, though singers never spontaneously isolate the words from their music as I have had to do here.?

The first of my examples was composed by the late Jack King, father of Archie King, the lone survivor of those who were 'made men' in 1914. His affectionately teasing song is about the way in which a certain woman, never mentioned by name but immediately recognisable to his audience, reveals her emotions by mentioning the town Ivanhoe. For each line of the song-words, three versions are given below. The first is the Ngiyambaa sentence, with boundaries between morphemes marked by hyphens and equals signs, as well as word-boundaries by spaces. The second is a morpheme-by-morpheme gloss which gives the meanings of roots in lower case, and the function of affixes by abbreviations or equivalents in upper case. ${ }^{8}$ Where two morphemes of the language coalesce in such a way that a boundary cannot be marked between them by a hyphen in the top Ngiyambaa line, their functional glosses in the second line are linked by a plus sign. The third line is a word-for-word literal translation, with nothing added unless it is enclosed in parentheses, and with nothing taken away.

5 Since late 1972 the last surviving speakers have been passing on their knowledge to me. What I have learnt is recorded in my 1977 thesis, and in a forthcoming volume on Ngiyambaa (Donaldson 1980).

6 See Donaldson 1980, Appendix B, for Ngiyambaa songs commenting on events as various as innovations in diet and the arrival of the first train in their country. Versions of songs from the Pilbara making reference to a similar range of events appear in von Brandenstein and Thomas 1977. Goddard (1934) presents other examples in his discussion of the historical context of Aboriginal songs.

7 Dr Alice Moyle kindly allowed me to study her collection of 'song-words' (based on unpublished and published sources up to 1970) and made musical notations for all the Ngiyambaa, Diyari and Yolyu songs whose texts are presented here. The notations and the tape-recordings on which they are based are deposited in the Library and Resource Centre of the Australian Institute of Aboriginal Studies, Canberra.

${ }^{8}$ See Appendix 1, which also explains the orthography used for texts and the choice of spellings for language names. 
a Ivanhoe-ka:=lu

I. $-\mathrm{IGNOR}=3 \mathrm{rdSg}+\mathrm{ERG}$

ngiyiyi

Did she say Ivanhoe?

say+PAST

b ngini-kala:-pu-na

ka:rika

wi:nji

here-PL+EST-UNIV=3rdSg

'right meat' man sit-PAST

All around those parts is where the man lived who was right meat

(for her).

c marathal-kila:

long ago-HYPOTH

panjtjit-ma-la-nhi

fancy it-VBLSR-RECIP-PAST

A long time ago it must be, they took a fancy to one another.

d wultuman-kila:

old woman-HYPOTH

punpi-nja-la

I suppose she's getting an old woman now.

In Ngiyambaa the first word of the sentence is the most salient, just as the most stressed word is in an English sentence. Thus: Ivanhoe-ka:=lu ngiyiyi is equivalent to 'Did she say Ivanhoe?' In lines b and $\mathrm{c}$ this salience of the first word is maintained in the translation by keeping the equivalent phrase in the first position.

The influence of English on the vocabulary can be seen in the verbstem panjtjitma-, from 'fancy it', and the noun-root wultuman, from 'old woman', both of which have been preferred to available Ngiyambaa equivalents.

The particles which are attached to the first word of a Ngiyambaa sentence to convert it from a simple statement to a question, hypothesis, exclamation, assertion, etc. are in evidence in lines a, c, and d. -ka: in line a, which marks a yes/no question, is glossed IGNOR because its function is ignorative. It indicates that the speaker does not know if 'Ivanhoe' is what has been said. It will be noticed that personal pronouns are also attached to the first word of the sentence. Pronoun boundaries are distinguished with an equals symbol.

It must be remembered that the text just presented is not only a partial record of the song; it is a partial record of a performance, or rather several performances. I have heard a number of people sing the song, including Lily Hampton, Eliza Kennedy and Sarah Johnson. The words given here are those I have heard used by the first two singers. Even a tape recording does not necessarily capture all the auditory elements of a single performance which both performer and audience would take for granted as part of it, let alone its social aspects. For instance, although my tape does not reveal it, when Sarah Johnson recorded this song she accompanied it by thumping her apron, which she had bundled into a tight wad on her thigh. 
Oral literature can only be recorded in performance, and no particular performance can be definitive. Different performances may differ in many ways. Sarah Johnson's version of the first line contained biyal, 'always', instead of the particle -ka: cited here; 'She always mentions Ivanhoe'. And patterns of performance are as important to note as variations: for instance, singers of Ngiyambaa songs consistently repeat a song several times in succession and end abruptly, resuming conversation without a pause.

The second song is by the late Fred Biggs. Its words are if anything even more economical than those of the first, plunging the listener straight into a vivid little scene whose participants can only be identified by what one of them is saying. This text is taken from a recording made by Eliza Kennedy.

a kapukara:ng-ku-ka:=nu: pala kapuka: bug-GEN-IGNOR=2ndSg+OBL head egg Do you have the brains of a bug?

b wi:-mi-nja sit-WATCH-PRES

(He) is sitting watching.

c wari:li-nja-pa:=na stand+ULT FOCUS-PRES-ASSERT $=3 \mathrm{rdSg}$ He's over there, upright!

d wara:y-wa:-kara $=1 u$ bad-EXCLAM-SENS EVID=3rdSg+ERG You can see he had a bad dream all right!

e warukay-dji=lu butt of tree- $\mathrm{ABL}=3 \mathrm{rdSg}+\mathrm{ERG}$

He is peering around the butt of (that) tree.

ngana-y there-YONDER

yarutha:miyi dream+PAST

ku:ngkaymi-ya watch from cover-PRES

The way in which we are to interpret 'stand' in line c is made quite clear by the preceding line. The man who is 'standing' is also sitting down. Actually the Ngiyambaa is even more subtly indirect than the English in the way it sets the scene, because Ngiyamba third person pronouns do not distinguish the sex of their referents (but rather their visibility). The only way in which we know that it is a man and not a woman who has had a bad dream is because of the song-maker's pun: the dreamer is capable of sitting and 'standing' simultaneously. As for the 'bad dream', there is badness and badness in both Ngiyambaa and English.

Another subtlety has also been lost in the translation of line c. In Ngiyambaa, if the action denoted by a verb is undertaken with some ulterior motive in mind, you add a suffix to the verb which allows you to go on to mention the focus of the behaviour. But you are not obliged to do so; you can let the listeners guess for themselves. To capture this, line c would have to read, 'He's standing over there for the sake of ...' 
The sort of detail which this song suggests to a Wangaaybuwan listener is revealed in the comments which Eliza Kennedy made after singing the song to a group of women, including younger women with less knowledge of Ngiyambaa, and myself. (Some interpolations in Ngiyambaa have been omitted.)

That was a nice little song, you know. Say we women was all over there, [pointing] and this fellow had a sleep and had this horrible bad dream, dreaming about women, see, and this is what he's doing, he's wari:linja with 'something'. He's going to do something about it, see, and he don't know how to get about it, that's why he's at this tree, sort of peeping around and seeing if he can catch my eye or yours.

\section{Translations from Aboriginal oral literature: the state of the art}

Getting to know the Ngiyambaa songs made me wonder - if a dwindling speech community whose traditions are nearly lost produces songs like these, what else has been going on in the rest of the continent? Anyone who attempts to answer this question must depend heavily upon written translations, whether or not they have been trained in Australian linguistics, and whether or not they have a knowledge of one or more Australian languages. The number of languages and their distribution, as already outlined, make such a situation inevitable. However, some knowledge of what to expect (and what to be surprised by) in Australian languages is extremely helpful in assessing translations.

What about the translations I have found? Their variety is more impressive than their quantity or quality. For a start, a translation may or may not be based on an available text in the language of origin. This text may or may not be written in a comprehensible orthography. Even if the orthography can be interpreted, the text may or may not be split up properly into words, let alone analysed according to its constituent morphemes. Any grammatical analysis there is may or may not be backed up by the existence of a grammar or dictionary for the language concerned.

Whatever its qualities, this text in an Australian language may or may not be based on a tape-recording, which may or may not have been made with a flat battery in the middle of a dog-fight. The tape may record simply a single performance of the item, specially laid on for the investigator alone. If the performance involves several participants, the tape may have caught only what the person nearest the microphone was up to.

Among features of the performance which the tape cannot record may be activities such as dancing, ceremonial behaviour, mime, the making of string figures, narrative gestures, and so on; and the text based on the tape may ignore many of the features which the tape did record: music, falsetto impersonations of women by male narrators, variation in speed and tone of narration, even narrative devices such as a stream of sounds (ngo ngo ngo ngo...), to indicate that a situation in a story goes on and on and on. 
The sum of knowledge about oral literature in Australian languages filters through a web of such contingencies. The complex linguistic situation makes it hard for an outsider to become familiar with the full range of resources drawn on in the compositions of even a tiny fraction of the communities of the continent, and the technical problems involved in making recordings are considerable. But at a more fundamental level, the feelings and opinions of English speakers in Australia have had a greater influence on the quantity and quality of translations.

An image from a Ngiyambaa song will provide an entry for the history of relevant attitudes, and at the same time alert us to their living legacy. The line is about the (Australian) red-breasted robin:

$\begin{array}{lll}\text { walung-gula:y } & \text { dhun-lugu } & \text { yuga-yuga-nha } \\ \text { walu-LIKE } & \text { tail-3rdSg+GEN } & \text { shift-shift-PRES }\end{array}$

(He) flirts his tail like (a) walu.

What is a walu, or alternatively, what are walu? (Ngiyambaa nouns are not specifically either singular or plural unless a number suffix is added.) On occasions $I$ have put this question to people unfamiliar with the language, inviting them to think of the first simile which comes into their heads to describe the motion of a robin's tail. The chances are that they will liken the robin's twitching tail movement to that of a fan, perhaps prompted by the English name of those close relatives of the robin with rather similar behaviour, the fantails. Rightly rejecting 'fan' as a translation for walu on the grounds that the type of fan referred to was not traditionally used or popularly adopted by Aborigines, such people I have questioned are likely to find themselves at a loss for confident suggestions.

The simile has to be translated with a paraphrase. Every Australian knows the way in which the bark of gum trees peels and hangs in narrow ribbons. In Ngiyambaa those narrow hanging ribbons have a name, walu. But why should the twitching of a robin's tail be likened to a walu? Well, it often happens that a walu which is hanging by a thread will catch a current of air and vibrate as if it had a life of its own.

Although we can probably all recognize the aptness of this simile when it is presented to us, it isn't readily accessible to us imaginatively when we are trying to think of a simile to describe the robin's tail ourselves. The vocabulary a language has is the product of the history and the cultural pre-occupations of its speakers; and its resources for simple snappy similes are in turn governed by its vocabulary.

When English speakers first came to Australia, they couldn't see the wood for the trees. They were horrified by the unfamiliar and the nameless. No less a person than Charles Darwin 
. . . was so appalled in January 1836 by the ... 'extreme uniformity in the character of the vegetation' and the bark of the trees hanging dead in long shreds which swung about in the wind, making the woods so desolate and untidy, that when he left our country he wrote in his diary that he did so 'without sorrow or regret'.

Forty years later Marcus Clarke is equally ill at ease in the Australian bush which he idealizes as pervaded by 'Weird Melancholy'. He too is distressed by walu. He gives a generally vague description of the horrors of the landscape, but one sentence runs: 'From the melancholy gum strips of white bark hang and rustle'. ${ }^{10}$

The story of English-speaking Australians' failure to accept walu as a proper and unalarming part of the landscape comes to a happy end with Judith Wright's poem 'Gum trees stripping'. Here walu provide a central suggestive image of seasonal change which is as natural as images of autumn leaves are to the poetry of England:

The hermit tatters of old bark

split down and strip to end the season; ${ }^{11}$

And Australian English is now fully equipped to name those features of the landscape which matter to its speakers, partly by re-using English names such as robin, partly by borrowing words from Australian languages, including a number such as galah (cila:) or beelah (bila:r) which occur in Ngiyambaa and some of its neighbour languages. But we still don't look like getting a handy word for passing references to walu.

Let us now return for a moment to Marcus Clarke's melancholy landscape, this time to learn something about the history of attitudes to the landscape's inhabitants. He gave a reason for finding it so drear:

In historic Europe . . . every rood of ground is hallowed in legend and in song ... But this our native or adopted land has no past, no story. No poet speaks to us. Do we need a poet to interpret Nature's teachings, we must look into our own hearts, if perchance we may find a poet there.

He also gave, in addition to a panoramic survey of the dreadful scene, a detail for us to focus on:

From a silent corner of the forest rises a dismal chant, and around a

fire dance natives painted like skeletons. All is fear-inspiring and gloomy.

Although these two quotations come from adjacent paragraphs, Marcus Clarke is so absorbes in the indulgence of his own unease that it never occurs to him that the dismal chanters in the corner of his silent forest

\footnotetext{
9 Clark 1976.

10 Clarke 1969: 33-37.

i] Wright 1971: 133 .
} 
are actually chanting something, or that what they are chanting may, like historic Europe's legend and song, hallow every rood of ground for them at least, if not for him.

Although art may flourish for art's sake, and translation is certainly an art, there is no such thing as translation for translation's sake. No one translates material from one language to another, particularly when the task is as arduous as it is in this field, unless they both value it themselves and feel that at least some speakers of the language they are translating it into will also do so. Marcus Clarke may have shown no interest whatsoever in the substance of the Aborigines' chants; how much more interested are today's Australians? In March 1977 The Bulletin asked a number of critics and writers whom they felt were the most undervalued authors in Australia today. ${ }^{12}$ Les Murray led off, saying 'Our most serious undervaluation is Aboriginal poetry . . . the poems set down in, say, Ronald Berndt's recent Aboriginal Love Poetry, mostly from Arnhem Land, and Strehlow's classic Songs of Central Australia. ${ }^{13}$

I would like to expand his point and put it slightly differently. Clearly we don't value such poetry enough to translate it in any quantity. But the reading public is dependent on translations for its knowledge of oral literature in Australian languages. Strehlow's was the first attempt to document the entire literature of a particular speech community and to distinguish its kinds. The anthropologists Ronald and Catherine Berndt, who have been publishing versions of Aboriginal literature from a variety of areas since the 1940 s, have had few competitors. ${ }^{14}$ With so little material available, the public may also find it difficult to know what to make of what material there is. It is an ironic but inescapable fact that the only acknowledged judges of a particular translation are those who have no need of one - the people who are equally at home in the language and culture of both the original and its translation. The opinions of such judges about translations from Australian languages can rarely be heard by the people who need them. Supposing the language of the original is still spoken, bilingual people belonging to the community concerned are often illiterate, or else they are not interested in the world of literary criticism or familiar enough with it to make their views known there. Most readers of available translations are simply not in a position to begin to evaluate Aboriginal oral literature.

12 The Bulletin, 5 March 1977: 64.

13 Berndt 1976a; Strehlow 1971.

14 Royalties from an abridgment of Love songs from Amhem Land will be used for an annual prize for Aboriginal students, to stimulate interest in traditional poetry and in innovative composition. The prize will be administered by the Aboriginal Arts Board (Berndt 1976b). 
But that is not the end of the matter. The fact that judgments about oral literature in Australian languages are exceedingly hard to make with assurance does not mean that people are unwilling to judge it. What presentations there are of the stories and songs of the Aborigines have often been approached with a zest for judgment which is rarely met with in other fields of literature.

In 1957 F.T. Macartney wrote an essay entitled 'Literature and the Aborigines', which was superficially a plea for rational assessment of their literary capacities, based on an appeal for reliable information as opposed to unsubstantiated assertions about the quality of their compositions. One of Macartney's targets was the Jindyworobak club, who were fiercely in favour of Aboriginal literature, on principle. Jindyworobak, in the words of the club's founder, Rex Ingamells, "is an Aboriginal word meaning "to annex, to join". The Jindyworobaks are those individuals who are endeavouring to bring Australian art into proper contact with its material'. ${ }^{15}$ In 1938 Ingamells prescribed the following approach to writing Australian poetry in English: "From Aboriginal art and song we must learn much of our new technique; from Aboriginal legend, sublimated through our thought, we must achieve something of a pristine outlook on life'. ${ }^{16}$ Macartney knows exactly how to pinpoint what is wrong with one of the techniques used by Ingamells when he tried to practise what he preached. Quoting a verse by Ingamells:

Far in moorawathimeering,

Safe from wallan darenderong

Tallabilla waitjurk wander

Silently the whole day long. Macartney ${ }^{17}$ comments:

The Aboriginal words, taken from one of the many dialects in printed vocabularies, mean nothing to the reader, and if they evoke any association at all, this is because he believes they are Aboriginal, though the effect would be the same if they were nothing of the kind but merely invented.

But his common sense deserts him when he comes to discussing Aboriginal literature itself. He takes as his text the 'Native Saying' at the beginning of Harney and Elkin's book Songs of the songmen: Aboriginal myths retold which the authors set out as follows:

15 Macartney 1967.

16 Ingamells 1969: 249, 264.

17 Macartney 1967: 65-66. 
Native saying: Mordja Amari Mordja / Ngu Borngga Amari Mordja. Literal Translation:

Paraphrase: He who loses his dreaming is lost. ${ }^{\text {F }}$.

Macartney's quotation is set out in the same way. He describes the top line as being in 'Aboriginal language transposed ... into writing'; then the second line, referring to it (as do the authors) as the 'literal translation'; then he introduces the third as ' . . the tidy shaping of this into the epigrammatic neatness of the line "He who loses his dreaming is lost" '. On the basis of these three lines set out in this fashion Macartney ${ }^{19}$ concludes that:

Apparently attempts at transliteration, the basis of all true translation, are abandoned as hopeless; for the impossibility of real equivalents, it must be remembered, is not just a matter of idiom, but the difference of a mentality expressing itself more like what we call the stream of consciousness than like our articulateness.

It does not seem to have occurred to him that Harney and Elkin may be guilty of a piece of mystification every bit as silly as Ingamells'. In fact the original language of this 'Native Saying' is nowhere identified, though the book includes a map which suggests that it could be any language from anywhere in the northern half of the Northern Territory. The principles of its transposition into writing are inadequately explained by the note on spelling which is provided. As for the so-called 'literal translation', it is clearly not such in the sense defined for the third lines of texts cited elsewhere in this essay; nor does it correspond to their second lines of morpheme-by-morpheme glosses. Far from reflecting anyone's stream of consciousness, this dollop of word-porridge demonstrates either the authors' lack of consciousness as to what a literal translation is, or their inability to construct one. The absence of 'articulateness' can safely be assumed to be theirs. ${ }^{20}$

Macartney has not understood that human languages simply do not differ as grossly as he imagines. What he calls transliteration need never be abandoned as hopeless, except by those who do not know the languages they are dealing with. Languages do not differ so fundamentally in what they are able to say but rather in what they must say. The difficulties of translation arise at the level where the source and target languages offer a different range of compulsory choices of grammatical form and vocabulary.

18 Harney and Elkin 1968 (first published 1949).

19 Macartney 1967: 63.

20 To be fair, there is evidence to suggest that Elkin was attempting a 'salvage operation' on Harney's manuscript to ensure publication in 1949. The revised edition contains a memoir of Harney, who died in 1962, in which the journalist Douglas Lockwood suggests that Harney was able to think like an Aboriginal (1968: 5).

21 The point is exemplified in my discussion of the second Ngiyambaa song, and is expanded in Jakobson 1959. 
They are difficulties of emphasis in communication, not of capacity to communicate. Twenty years after Macartney wrote one can hope that the level of general knowledge about such basic linguistic matters has risen sufficiently to prevent such misconceptions.

What is interesting about Macartney's judgment is not its wrongness, but its naturalness, given that he is not very sophisticated about the nature of language. If you assume that Harney and Elkin did a good job, and if you have not come across any thing to disabuse you of your linguistic misconceptions, a judgment like Macartney's, given the evidence, is not only valid but inescapable. Apart from the grossness of his generalization from one 'Native Saying' to the literature of a continent, his final summing-up is not unfair:

To claim that this, or any other utterance in Aboriginal language, is 'capable of great strength and beauty, which can rise to great heights of feeling, ${ }^{22}$ or to suggest that it can have literary quality, is certainly to be doubted, as it certainly has not been demonstrated. All records of oral literature require extensive documentation regarding performance, composition, transmission and the like. In addition, those who make translations from oral literature in languages which are neither widely spoken nor written have to prove that they really are translations. They need to be underpinned by the best that can be done in the way of original texts, grammars, dictionaries, tape-recordings, film and contextual accounts. Unless translations are undertaken in connection with activity of this kind on a considerable scale it will continue to be possible to blame the Aborigines for any defects in translators' presentation of their literature and, conversely, to attribute their achievements to translators' embellishments. The continuing oral transmission of most Aboriginal vernacular literature is threatened by social changes, despite the renewed commitment of some communities to their languages. If future generations are to have trustworthy records of what still survives, they need to be made now.

\section{Aboriginal poetics and translation}

So far, I have concentrated on the problems that confront nonAboriginal people trying to find out about Aboriginal oral literature. I have mentioned the way in which the multiplicity of Australian languages, and the linguistic situation generally, affect the quantity and quality of translations. I would like now to point out how culture-bound my whole argument has been. It is typical of the members of a large monoglot culture to feel that the best way to respond to compositions in another language is to translate them. This is sensible communicative economics.

22 The quotation comes from Strehlow's introduction to his 1947 volume. Whatever the literary merits of the original utterance, the phrase "He who loses his dreaming is lost' evidently has a certain appeal. The Australian folksinger Gary Shearston used it in a song entitled 'A borigine' in the LP 'Dingo' released by Charisma in 1975. 
Let us now turn to the speakers of these multifarious languages themselves. How do they react to the linguistic map, or their part of the map? What sort of communicative economics do they practise? Aboriginal attitudes both to the composition of oral literature and to its transmission seem to me to be intimately linked with their experience of multilingualism; attitudes which reveal, for those brought up on literature in English, whether written or oral, a novel emphasis on how words may be used in songs. ${ }^{23}$

All songs and many kinds of story are property in Aboriginal Australia. There is much regional variation but there are basically two types of ownership. The first type is collective, in association with ownership of land. Ownership of myths concerning ancestral journeys and their associated songs may be divided up and spread over a wide area crossing linguistic boundaries. Thus songs with more or less identical words may be sung in ceremonies by people who otherwise speak different languages or dialects. The second type of ownership is individual ownership by the composer. Songs owned in this way are, or were, of ten traded over large areas, with people sometimes setting out on considerable journeys to collect new songs. They are learned verbatim in the languages in which they are composed, maybe with some pronunciation changes to make them conform to the sound system of the learner's language.

There is thus no automatic reaction of alarm to the notion of singing a song some or all of whose words one cannot understand. One may learn a song and its interpretation as two separate items. Indeed, words or whole songs in other languages may sometimes be positively preferred. The English loan words encountered in the first Ngiyambaa song were being widely adopted in ordinary conversation at the time when it was composed. But an Aboriginal preference for using words from other languages is as likely to be linked with their being less well known and understood. Ironically, the only phrase which is now fully construable in the words of a song from the Port Augusta district transcribed by Daisy Bates is the borrowed 'Captain on a rough sea'. ${ }^{24}$ Ian Crawford writes of a ritual song used in the Kimberleys with words which do not belong to any local dialect. Though its singers were unable to tell him what these words

\footnotetext{
23 I have emphasised song texts in this paper for practical reasons only: it is relatively easy to find short examples which can be appreciated without special knowledge of their cultural origins, despite the drawback that they are isolated here from their vocal and instrumental music. Indeed, their musical form probably saves them from a common fate of narratives - which is to undergo a series of re-workings progressively less faithful to the original tellings. One of the most widely available collections consists entirely of stories retold from other printed versions: Reed (1965: 5) admits that 'In a few cases the story may ... be of a composite character' because amalgamated from different sources.
}

24 Bates collection (ANL MS 365-35, n.d.: 38 ). 
meant, they turned out to be interpretable if assumed to be in Malay, meaning something like 'At the call to prayers, perform ablutions, take on fragrance, it is the holy time'. ${ }^{25}$

Where preferences for exotic language play a large part in poetics, they are often accompanied by preferences for other types of esoteric language. There may be room for multiple interpretations. This possibility may be institutionalised, so that some types of song are always interpretable at several different levels. Certain layers of meaning, or even the song itself, may be withheld from certain people for specific reasons, such as their sex or inferior ceremonial status. ${ }^{26}$

As a result, the words of some kinds of Aboriginal songs present a whole new dimension of tasks for the 'translators'. Instead of providing literal translations, they have to document interpretations. They have to establish the limits of interpretability, for Aboriginal songs mayalso contain 'nonsense' elements, in the same way as (for instance) folk songs in English have fol-de-rol refrains. And they must explain what they can about the history of forms which differ from those encountered in the ordinary spoken language of the singers. Aborigines in some regions may say some such words go back to the 'dreamtime'. But in view of the degree of Aboriginal interest in exotic language any assumption that unusual language in songs is archaic (i.e. that it has been transmitted verbatim from generation to generation while changes have been taking place in non-literary language) needs rigorous proof. ${ }^{27}$

My final examples will illustrate some of these points. They are of two very different kinds of song, one from South Australia and one from the Northern Territory. But like the Ngiyambaa songs, they are all individually composed, and sung by the composer during his lifetime. They all involve a minimum of accompaniment and their performance does not require dancing or the participation of more than one performer. And none of them has ceremonial significance or 'inside' interpretations which it would be improper for an outsider to know or reveal.

The three South Australian songs were composed by the late Leslie Russell, one of the last knowledgeable speakers of Diyari, from the country around Cooper's Creek. He sang and explained them to Peter Austin, who has written a linguistic study of Diyari. ${ }^{28}$ Peter Austin transcribed them and provided the information presented here. The songs are designed

25 Crawford 1969: 316. Macknight (1972: 301) mentions a number of instances of Macassan ritual formulae being used in ceremonies in Arnhem Land by Aborigines who do not know their exact meaning.

26 See for instance Keen 1977.

27 A range of possible sources for 'phonological peculiarities' of Yir-Yoront song words is canvassed by Alpher (1976).

28 Austin 1978. 
to be accompanied by a pair of clicked boomerangs. They evoke an image or an incident with very few words indeed, used according to strict rules of composition. These words may be cited in conversation to identify the song, like the title or first line of a song in English.

The first song uses only four disyllabic words, which will doubtless seem cryptic at first sight.

\section{ngapa kudu}

water hole

thupu thupu

smoke smoke

But their choice is readily understood once one knows what scene is being evoked. ngapa kudu thupu thupu refers to a traditional technique for clearing muddy water. Gypsum burnt to a powder was thrown into the water-hole to settle the impurities as a sediment at the bottom of the water. When the gypsum was thrown in, a 'smoke' rose from the surface of the water. This, Leslie Russell explained, happened 'before the whites took the country'.

When the song is sung a meaningless sound is inserted between each word - ngapa nga kudu nga thupu nga - and the words are repeated as often as the singer fancies. When the singer draws a breath, or finishes his performance, he knocks off the final syllable of the final word and substitutes a glottal stop, for instance thu instead of thupu.

The next song contains three words:

ngapa puwa

water bore

kurrpindani

rainbow

It commemorates the drilling of a bore at Mt Gason near the Birdsville track about sixty years ago. The composer, who was present, saw a rainbow in the first jet of water that gushed out. The previous song was made up of exclusively disyllabic words, so that the sound nga always occurred between words. Here, the third word, kurrpindani, 'rainbow', has four syllables. nga is inserted after the second vowel of the second syllable ngapa nga puwa nga kurrpi nga ndani nga - and so on, always finishing on a word truncated with a glottal stop.

Another point to note about this song is that just as Jack King chose English words in preference to Ngiyambaa in the song about Ivanhoe, Leslie Russell has chosen a word from the neighbouring language Wanganuru for 'rainbow' in preference to the word for 'rainbow' in Diyari, kurikira, which also has four syllables. So of the three words of the song two are not Diyari - since puwa comes from English 'bore'. 
In the final example chosen to illustrate this type of song, the composer imagines himself the victim of a revenge party who sneak silently up on him wearing what English speakers know as "kadaitja shoes' and strike him on the back of the neck, so as to kill him in such a way that his tongue protrudes, like a bullock's when it is slaughtered, as Leslie Russell reminded Peter Austin after singing him the song. ${ }^{29}$

$\begin{array}{ll}\text { pinja-li } & \text { [la] } \\ \text { revenge } & \text { party-ERG [la] } \\ \text { nganha } & \text { diya } \\ \text { me } & \text { strike } \\ \text { thali } & \text { thali } \\ \text { tongue } & \text { tongue }\end{array}$

The first two lines consist of a fully grammatical transitive sentence, pinjali nganha diya, 'the revenge party strikes me'. The word pinja, meaning 'revenge party', the agent of the sentence, carries the ergative case inflection -li. (Before one tape-recorded performace of the song, Leslie Russell gives a spoken version of this sentence, in which he changes the word-order, placing nganha, 'me', at the beginning of the sentence. This is because he is explaining to Peter Austin that 'It's me the revenge party strikes'.)

The word pinjali with its ergative case inflection is trisyllabic. When this line is sung nga is inserted at the morpheme-boundary between the root pinja and the inflection -li, and an extra syllable la is added to make this form disyllabic. (The exact form of such an extra syllable varies depending on the nature of the form which it expands.) The words which constitute a sentence form an inseparable unit, but the line 'tongue tongue' may follow or precede them or be omitted altogether in any given repetition of the words within a performance of the song.

I have been at pains to explain the formal composition of these songs, but I have not indicated the range of topics they cover. Just to point out the difficulty of making generalizations as to the scope of their themes, I should mention that a similar Wayganuru song records the impression made on the composer by watching a white woman come out of the door of her house and proceed to wash it. ${ }^{30}$

29 In 1969 Luise Hercus tape-recorded an earlier, more vigorous performance of this song in which Leslie Russell sings it with Jimmy Russell, his 'brother' according to Diyari terms, his first cousin according to English usage.

30 Also tape-recorded by Luise Hercus. 
Now to end with a glimpse of a less threatened tradition. My example comes from a community in north eastern Arnhem Land where the vernacular is still alive and well. It is a song recently composed by someone in his teens, David Marrputja Munungurr. He speaks Djapu, a Yolnu language. Frances Morphy, who is working on a description of Djapu, ${ }^{31}$ recorded him singing the song and provided the text and explanatory information. $^{32}$ Her translation is literal in the same way that the translations of the Ngiyambaa songs were. It reads as a simple description of pelicans journeying along loading their pouches with fish and running in an attempt to take off and fly. The pelican's pouches are referred to as fishing nets, an obvious image if we consider both the purpose of the pouch and the shape of the local fish nets, which consist of a net scoop suspended from two rods hinged together at one end.

a $\mathrm{m}$.....

b nhirrppa-n

marrtjtji kanjpu-w

manța

ka:lumay

put in-PAST

go+PAST fishing net-DAT they+DUAL pelican

thirrippi-wu

inside-DAT

Two pelicans went along putting (fish) into their fishing nets.

c nhirrppa-n marrtjtji Palmi-lil thakkal-lil nhirrppa-n put in-PAST go+PAST P.ALL cheek-ALL put in-PAST (They) went to Palmi putting fish in (their) pouches.

repeat a

d tjuța tjuța tjuța tjuța creep creep creep creep

(They) crept along

e thakkal-lil nhirrppa-n Palmi-lil cheek-ALL put in-PAST P.-ALL

putting (fish) into (their) pouches (as they went) to Palmi

f kuku-lil katjtjuy pala e e Wankurr-lil come+IMP-ALL go away+IMP away W.-ALL

Come on! Away (you) go to Wankurr.

g m.... thu ....

h nhirrppa-n marrtjtji kanjpu-w

put in-PAST go+PAST fishing net-DAT

(They) went along putting (fish) in their fishing nets.

31 Morphy n.d.

32 John Lirpiya Munungurr, while a student at the School of Australian Linguistics, checked the text and resolved an outstanding translation problem. 


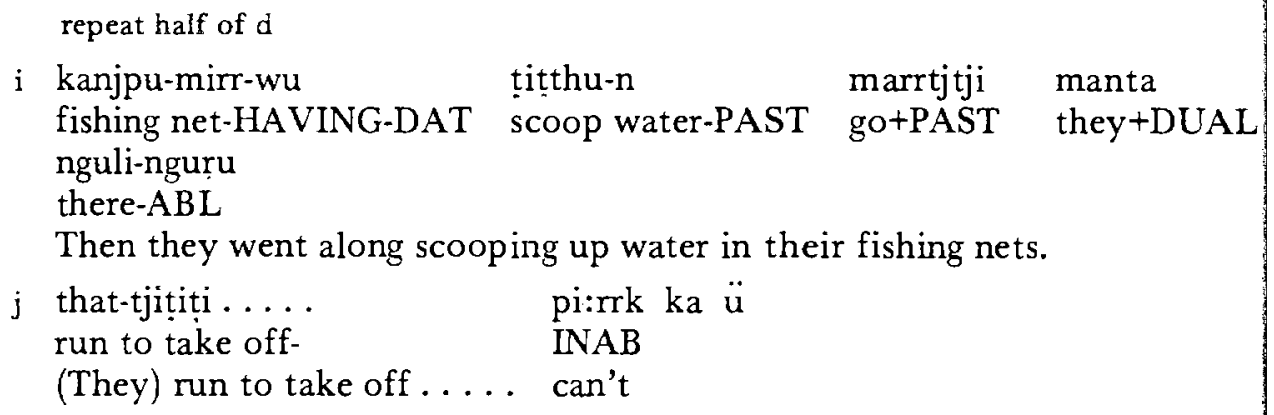

marrtjti manta go+PAST they+DUAL

ngilimurrung-ku ka:lumay we+PL+EXC-DAT pelican

1 nhirrppa-n marrtjtji kanjpu-w wangu nhirrpp-ul put in-PAST go+PAST fishing net-DAT pouch put in-PAST (They) went along putting (fish) in their fishing nets, dipping their pouches.

repeat $j$ twice, repeat $k$, repeat 1 .

There is a problem at line k. Who is big brother, and why is he asked to fix pelican? It is helpful to recall that song-words are sometimes intended to be interpreted on more than one level at once. It is also necessary to know that the author, Marrputja's, father owns a yellow Toyota called ka:lumay, i.e. 'Pelican' and that all Yolgu cars are given names (the same names which were formerly given to canoes), and each clan has a set of these names. As well as being about pelicans, this song is also an account of a particular journey that Marrputja once made in the Toyota named Pelican, when his older brother was driving it. Lines a to $h$, where the pelicans fill their pouches, describes the car loading up with passengers, and the place-names mentioned are those through which this particular journey took them. At one point in the journey the ground was very wet. At line $i$ where the pelicans scoop up water, ka:lumay the Toyota gets bogged. At line $j$ the pelicans attempt to get airborne and the driver of the Toyota puts his food down hard, revs the engine and tries to get it out of the mud. Though it may not be obvious from the transcription of the words alone, this line when sung is superbly onomatopoeic at both levels of interpretation. The form pi:rrk has the literal meaning 'can't' and can be understood, together with the following two syllables, which are present for their sound effect only, as an expression uttered by either the pelicans, or the Toyota. (Note that the verb in this onomatopoeic line is uninflected, as also at line d. Such uninflected forms 
would not occur in similar circumstances in the spoken language.) So the plea at line $\mathrm{k}$ is the only part of the song which depends exclusively on the car-journey interpretation. It is made on behalf of the passengers in the Toyota, asking the driver to fix it and get them out of the mud so they can continue their journey.

Pelican's is not the only journey which calls for special skills. The guidance of those in a position to make recordings and translations is vital if we are to make our way towards a better understanding of oral literature in Australian languages.

\section{AUSTRALIAN INSTITUTE OF ABORIGINAL STUDIES}

\section{APPENDIX 1}

All song-texts are set out in the same format whatever the language, using the same orthographic conventions, and the same abbreviations or equivalents for affix functions wherever practicable, thus affording a small opportunity for conclusions about likely recurrent characteristics of Australian sound systems and grammars.

Orthography (phonemic for each language)

A colon following a vowel indicates that the vowel is long. A dot under a consonant, for example $r$, indicates retroflexion of the tongue. Voiced $\mathrm{d}$ and $\mathrm{d}$ contrast with voiceless $\mathrm{t}$ and $\mathrm{t}$ intervocalically in Diyari. There is no voiced/voiceless contrast among stop consonants elsewhere in Diyari or in any of the other languages represented in this article. The voiceless series of symbols $p, t, k$ is used to write them here. The following digraphs are used to represent certain consonants:
th interdental laminal stop
tj alveo-palatal laminal stop
nh nasal corresponding to th
nj nasal corresponding to tj
that, thin
jam
ng velar nasal
rr trilled
onion
$\operatorname{sink}$, sing

closest sound in English

The spelling used for language names is that favoured by speakers of the language wherever there is vernacular literacy. Where this is restricted or non-existent, the spelling follows that found in the most authoritative scholarly work on the language concerned. 
Affix functions

\begin{tabular}{|c|c|c|}
\hline \multirow[t]{5}{*}{ Particles } & IGNOR & Ignorative \\
\hline & HYPOTH & Hypothesis \\
\hline & ASSERT & Assertion \\
\hline & EXCLAM & Exclamation \\
\hline & SENS EVID & $\begin{array}{l}\text { Speaker has sensory evidence for } \\
\text { statement }\end{array}$ \\
\hline \multirow{6}{*}{$\begin{array}{l}\text { Person, } \\
\text { Number }\end{array}$} & INAB & Subject's inability to perform action \\
\hline & 2ndSg & Second person singular \\
\hline & $3 \mathrm{rdSg}$ & Third person singular \\
\hline & DUAL & Dual \\
\hline & PL & Plural \\
\hline & EXC & Exclusive of addressee \\
\hline \multirow{6}{*}{$\begin{array}{l}\text { Verb } \\
\text { suffixes }\end{array}$} & PAST & Past tense \\
\hline & PRES & Present tense \\
\hline & RECIP & Reciprocal \\
\hline & NOW & 'Now' \\
\hline & WATCH & 'Watching' \\
\hline & ULT FOCUS & Ulterior focus \\
\hline \multirow[t]{6}{*}{ Case forms } & ERG & $\begin{array}{l}\text { Ergative (subject of transitive } \\
\text { sentence) }\end{array}$ \\
\hline & GEN & Genitive \\
\hline & OBL & Oblique \\
\hline & $\mathrm{ABL}$ & Ablative \\
\hline & DAT & Dative \\
\hline & ALL & Allative \\
\hline \multirow[t]{2}{*}{$\begin{array}{l}\text { Determiner } \\
\text { suffixes }\end{array}$} & EST & $\begin{array}{l}\text { Reference of determiner has been } \\
\text { established }\end{array}$ \\
\hline & YONDER & 'Yonder' \\
\hline Miscellaneous & $\begin{array}{l}\text { UNIV } \\
\text { HAVING }\end{array}$ & 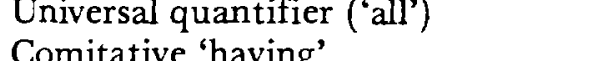 \\
\hline
\end{tabular}

Further explanation of suffixes occurring in the Ngiyambaa texts can be pursued in Donaldson 1980.

\section{BIBLIOGRAPHY}

Alpher, Barry. 'Phonological peculiarities of Yir-Yoront song words', in Sutton, Peter ed. Languages of Cape York. Canberra, 1976: 78-83.

Austin, Peter K. A grammar of the Diyari language of north-east South Australia. Australian National University, $\mathrm{PhD}$ thesis, 1978.

Bates, Daisy M. Daisy M. Bates Collection, National Library of Australia. Songs and dances, Western Australia, Section XI, Ia ANL MS 365-35.

Beckett, Jeremy. 'Further notes on the social organisation of the Wongaibon of western New South Wales', Oceania, 29 (3). 1959:200-207. 


\section{TRANSLATING ORAL LITERATURE}

Berndt, Ronald M. Love songs of Arnhem Land. Melbourne, $1976 \mathrm{a}$ Three faces of love. Melbourne, 1976b.

Clark, Manning. A discovery of Australia (The Boyer Lectures 1976). Sydney, 1976.

Clarke, Marcus. 'Preface to Gordon's Poems 1876' in Barnes, John ed. The writer in Australia. Melbourne, 1969:33-37.

Crawford, Ian M. Late prehistoric changes in Aboriginal cultures in Kimberley, Western Australia University of London, PhD thesis, 1969.

Dixon, R.M.W. The languages of Australia, Cambridge, 1980 (in press).

Donaldson, Tamsin. A description of Ngiyamba:, the language of the Wanga:y buwan people of western central New South Wales. Australian National University, $\mathrm{PhD}$ thesis, 1977.

Ngtyambaa, the language of the Wangaaybuwan people of New South Wales. Cambridge, 1980 (in press).

Goddard, Roy H. 'Aboriginal poets as historians', Mankind, 1 (10), 1934:243-246.

Gordon, Adam Lindsay. Sea spray and smoke drift. Melbourne, 1876.

Harney, Bill and A.P. Elkin. Songs of the songmen: Aboriginal myths retold. Melbourne, 1968 (1 st published 1949).

Ingamells, Rex. 'Conditional culture (1938)', in Barnes, John'ed. The writer in Australia. Melbourne, $1969: 245-265$.

Jakobson, Roman. 'On linguistic aspects of translation', in Brower, Reuben A. ed. On translation. Cambridge (Mass.), 1959:232-239.

Keen, Ian. 'Ambiguity in Yolngu religious language', Canberra Anthropology, 1 (1), 1977:35-50.

Macartney, F.T. 'Literature and the Aborigines', in Semmler, Clement ed. Twentieth century Australian literary criticism. Melbourne, 1967:55-66.

Macknight, C.C. 'Macassans and Aborigines', Oceania, 42 (4), 1972:283-321.

Morphy, Frances. 'Djapu', in Dixon, R.M.W. and B.J. Blake eds. Handbook of Australian languages. Volume 2. n.d. (forthcoming).

Reed, A.W. Aboriginal fables and legendary tales. Sydney, 1965.

Strehlow, T.G.H. Aranda traditions. Melbourne, 1947. Songs of central Australia. Sydney, 1971.

Sutton, Peter. 'How many Aboriginal languages are there', Aboriginal News, 2 (1), 1975:22-23.

Wik: Aboriginal society, territory and language at Cape Keerweer, Cape York Peninsula, Australia. University of Queensland, $\mathrm{PhD}$ thesis, 1978.

Tindale, Norman B. Aboriginal tribes of Australia. Canberra, 1974.

von Brandenstein, C.G. and A.P. Thomas. Taruru: Aboriginal song poetry from the Pilbara. Adelaide, 1974.

Wright, Judith. Collected poems 1942-1970. Sydney, 1971. 